\title{
Conferring indirect allospecificity on CD4+CD25+ Tregs by TCR gene transfer favors transplantation tolerance in mice
}

\author{
Julia Yuen-Shan Tsang, ${ }^{1}$ Yakup Tanriver, ${ }^{1}$ Shuiping Jiang, ${ }^{1}$ Shao-An Xue, ${ }^{2}$ Kulachelvy Ratnasothy, ${ }^{1}$ \\ Daxin Chen, ${ }^{3}$ Hans J. Stauss, ${ }^{2}$ R. Pat Bucy, ${ }^{4}$ Giovanna Lombardi, ${ }^{1}$ and Robert Lechler ${ }^{1}$ \\ ${ }^{1}$ MRC Centre in Transplantation, King's College London, Guy's Campus, London, United Kingdom. \\ 2Department of Immunology and Molecular Pathology, Hampstead Campus, University College London, London, United Kingdom. \\ ${ }^{3}$ Department of Immunology, Hammersmith Campus, Imperial College London, London, United Kingdom. ${ }^{4}$ Department of Pathology, \\ University of Alabama at Birmingham, Birmingham, Alabama, USA.
}

\begin{abstract}
T cell responses to MHC-mismatched transplants can be mediated via direct recognition of allogeneic MHC molecules on the cells of the transplant or via recognition of allogeneic peptides presented on the surface of recipient APCs in recipient MHC molecules - a process known as indirect recognition. $\mathrm{As} \mathrm{CD4}^{+} \mathrm{CD} 25^{+}$Tregs play an important role in regulating alloresponses, we investigated whether mouse Tregs specific for allogeneic MHC molecules could be generated in vitro and could promote transplantation tolerance in immunocompetent recipient mice. Tregs able to directly recognize allogeneic MHC class II molecules (dTregs) were obtained by stimulating $\mathrm{CD} 4^{+} \mathrm{CD} 25^{+}$cells from $\mathrm{C} 57 \mathrm{BL} / 6$ mice $\left(\mathrm{H}-2^{\mathrm{b}}\right)$ with allogeneic $\mathrm{DCs}$ from $\mathrm{BALB} / \mathrm{c}$ mice $\left(\mathrm{H}^{2} \mathrm{2}^{\mathrm{d}}\right)$. To generate Tregs that indirectly recognized allogeneic MHC class II molecules, dTregs were retrovirally transduced with TCR genes conferring specificity for $H-2 K^{d}$ presented by $H-2 A^{b}$ MHC class II molecules. The dual direct and indirect allospecificity of the TCR-transduced Tregs was confirmed in vitro. In mice, TCRtransduced Tregs, but not dTregs, induced long-term survival of partially MHC-mismatched heart grafts when combined with short-term adjunctive immunosuppression. Further, although dTregs were only slightly less effective than TCR-transduced Tregs at inducing long-term survival of fully MHC-mismatched heart grafts, histologic analysis of long-surviving hearts demonstrated marked superiority of the TCR-transduced Tregs. Thus, Tregs specific for allogeneic MHC class II molecules are effective in promoting transplantation tolerance in mice, which suggests that such cells have clinical potential.
\end{abstract}

\section{Introduction}

Naturally occurring $\mathrm{CD} 4{ }^{+} \mathrm{CD} 25^{+}$Tregs are known to play a key role in preventing autoimmunity. In recent years, several groups have reported that this population of cells can also be exploited to promote transplantation tolerance in experimental models (1). Indeed, clinical protocols have been developed in hematopoietic stem cell transplantation using polyclonal $\mathrm{CD} 4^{+} \mathrm{CD} 25^{+} \mathrm{T}$ cells to inhibit graft-versus-host disease (GVHD) (2-4). However, in experimental models of transplantation tolerance in which the tolerance can be transferred by $\mathrm{CD} 4^{+} \mathrm{T}$ cells, the effect is highly specific, suggesting that expanding $\mathrm{CD} 4^{+} \mathrm{CD} 25^{+}$Tregs with specificity for donor alloantigens would lead to a significant gain in efficiency $(1,5,6)$.

In the alloresponse to $\mathrm{MHC}$ antigens, 2 pathways are involved (7). "Direct pathway" refers to the recognition of donor MHC molecules, intact, on the surface of donor cells. This induces vigorous responses at a very high frequency, driving the mixed lymphocyte response in vitro and early transplant rejection in vivo. The indirect response occurs when donor alloantigens are internalized by recipient APCs, processed, and presented as peptides by recipient MHC molecules. This is a low-frequency response but can be clonally expanded over time. Immune monitoring of patients who had undergone transplantation suggests that it is the indirect alloresponse that is the major immune driver of chronic rejection and

Nonstandard abbreviations used: BL/6, C57BL/6; MST, median survival time. Conflict of interest: The authors have declared that no conflict of interest exists. Citation for this article: J. Clin. Invest. 118:3619-3628 (2008). doi:10.1172/JCI33185. poses the major threat to long-term survival after transplantation $(8,9)$. Furthermore, the groups that have attempted to define the specificity of the $\mathrm{CD} 4^{+} \mathrm{T}$ cells that can transfer tolerance in rodent models have concluded that they have indirect allospecificity $(6$, $10,11)$. Based on these observations, the induction of regulatory cells with specificity for the indirect anti-donor response is likely to be a key component of a successful tolerance protocol.

Although indirect allospecificity can be enriched in $\mathrm{CD} 4^{+} \mathrm{CD} 25^{+}$ Tregs by repetitive stimulation with autologous DCs pulsed with peptide alloantigen, as we have previously described, this is inefficient due to the tendency for autoreactive cells to expand (12-15). In this study, we explored an alternative approach to the generation of regulatory cells with indirect allospecificity. TCR cDNA clones were isolated from a TCR-transgenic mouse strain whose T cells have indirect specificity for the $\mathrm{K}^{\mathrm{d}}$ molecule presented by $\mathrm{H}-2 \mathrm{~A}^{\mathrm{b}}$. These were cloned into retroviral vectors and used to transduce $\mathrm{CD} 4{ }^{+} \mathrm{CD} 25^{+}$Tregs. Using this approach, we show that allospecific Tregs in combination with short-term systemic immunosuppression can induce indefinite heart allograft survival. Although Tregs with direct anti-donor specificity prolonged graft survival, addition of indirect allospecificity by TCR transduction led to substantially greater efficacy.

\section{Results}

$C D 4^{+} \mathrm{CD} 25^{+}$Tregs with indirect allospecificity can be generated by retroviral transduction of TCR genes. In this study, 3 different Treg lines were used. The autoreactive Treg line (autoTreg) and the Treg line 

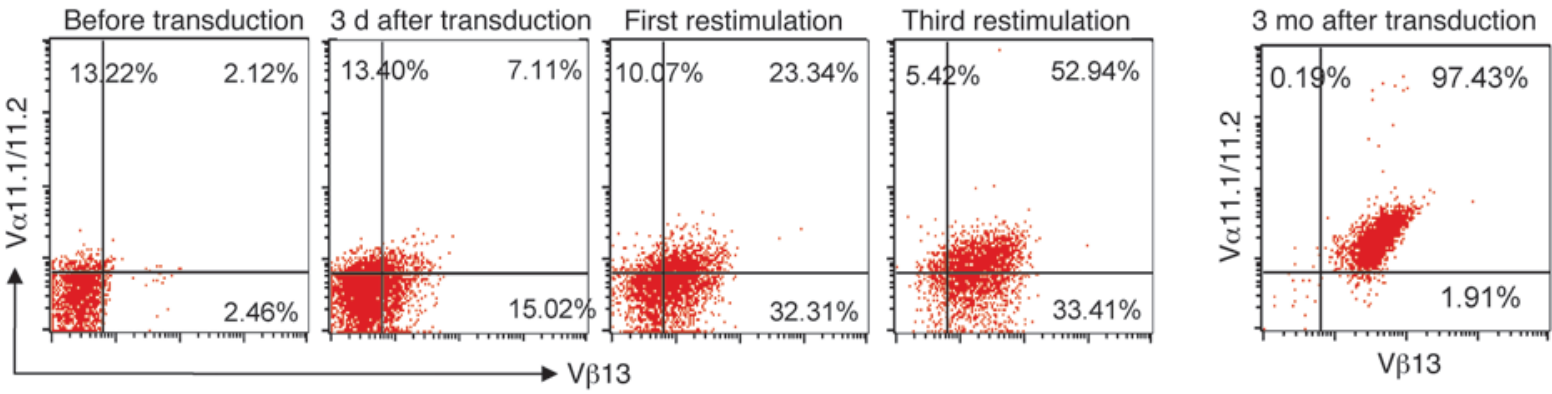

Figure 1

Expansion of Treg population expressing the transduced TCR $\alpha$ and $\beta$ chain after retroviral transduction. Direct allospecific Treg lines were transduced with genes encoding $\mathrm{K}^{\mathrm{d}}{ }_{54-68}$ indirect allospecific TCR $(\mathrm{V} \alpha 11.2 / \mathrm{V} \beta 13)$ chains and were restimulated weekly with $\mathrm{K}^{\mathrm{d}}$ peptide-pulsed immature BL/6 DCs. To detect surface expression of the transduced TCR genes, the cells were triple stained with anti-mouse V $\beta 13-\mathrm{FITC}, \mathrm{V} \alpha 11.1 / 2-\mathrm{PE}$, and anti-CD4-APC at different time points. Only CD4+ populations were gated for analysis. The percentage of cells in each quadrant is indicated.

with only direct allospecificity (dTreg) were generated by expanding in vitro $\mathrm{CD} 4{ }^{+} \mathrm{CD} 25^{+}$cells purified from $\mathrm{C} 57 \mathrm{BL} / 6(\mathrm{BL} / 6)$ spleen and lymph node cells with autologous $(\mathrm{BL} / 6)$ and allogeneic $(\mathrm{BALB} / \mathrm{c})$ DCs, respectively. A third Treg line with dual specificity $[\mathrm{d}$ Treg(TCR)] was generated by TCR transduction as described below. TCR $\alpha$ and $\beta$ chain cDNA clones were isolated from the $\mathrm{T}$ cells of TCR34 transgenic mice and subcloned into a myeloproliferative sarcoma virus-based retroviral vector (pMP71-PRE). This TCR has specificity for a peptide of $\mathrm{K}^{\mathrm{d}}$ presented by $\mathrm{H}-2 \mathrm{~A}^{\mathrm{b}}$. In order to generate Tregs with both a direct and an indirect allospecificity for $\mathrm{H}-2^{\mathrm{d}}$ alloantigens, the line with direct allospecificity was transduced with the TCR-encoding retroviruses.

After 1 round of TCR retroviral transduction, $7 \%-15 \%$ of the Tregs expressed both transduced TCR $\alpha(\operatorname{V} \alpha 11.2)$ and TCR $\beta$ (V $\beta 13$ ) chains, as shown by flow cytometric

\section{Figure 2}

TCR transduction conferred indirect allospecificity to direct allospecific Treg lines. (A) TCRtransduced Tregs [dTreg(TCR), black bars] were cocultured with mature BL/6 DCs in the presence of different amounts of $\mathrm{K}^{\mathrm{d}}$ peptide. $T$ cell proliferation was measured at day 3 by $\left[{ }^{3} \mathrm{H}\right]$ thymidine incorporation. GFP-transduced Tregs [dTreg(GFP), gray bars] and nontransduced direct allospecific Tregs (dTreg, white bars) were used as controls. Error bars represent mean \pm SD of experiments performed in triplicate. (B) CFSE-labeled TCR-transduced Tregs, nontransduced direct allospecific Tregs, and $\mathrm{K}^{\mathrm{d}}$ peptide-pulsed DCs expanded indirect allospecific Tregs (DCiTreg) were cocultured with mature $\mathrm{BL} / 6 \mathrm{DCs}, \mathrm{K}^{\mathrm{d}}$ peptide-pulsed BL/6 DCs $(1 \mathrm{mg} / \mathrm{ml}), B A L B / c$ DCs, or CBA DCs. The cells were harvested at day 4 of the coculture and stained with anti-CD4-APC and propidium iodide (PI). CFSE dilution of the cells was assessed by flow cytometric analysis. Only $\mathrm{CD} 4{ }^{+} \mathrm{PI}^{-}$populations were gated for analysis. Bracket regions indicated each cell division.

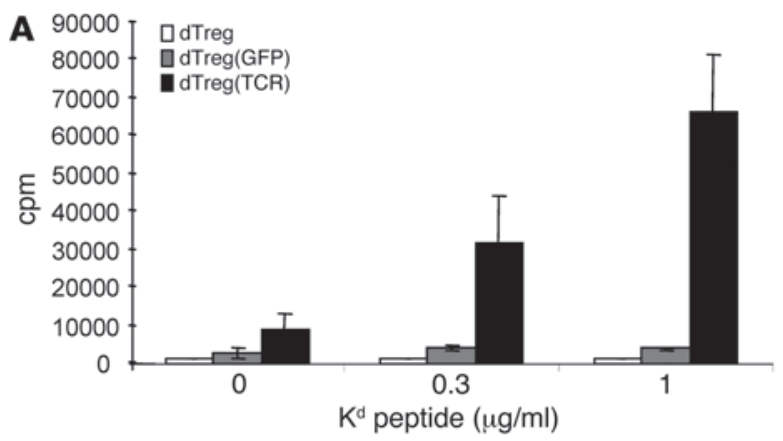

B
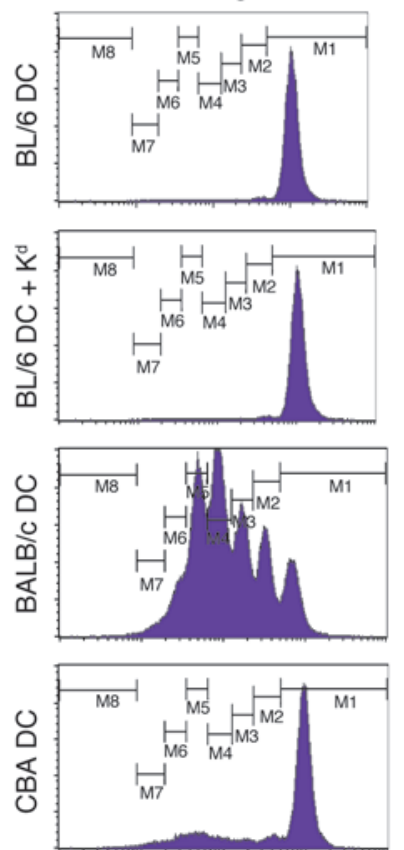

analysis (Figure 1). Restimulation of the TCR-transduced Tregs with $\mathrm{K}^{\mathrm{d}}$ peptide-pulsed immature BL/ 6 DCs increased the percentage of TcR $\alpha 11.2^{+} \mathrm{TcR} \beta 13^{+}$cells. After 3 stimulations, over $50 \%$ of the Tregs expressed the transduced TCR. The expansion of the Treg population expressing the transduced TCR indicated that retroviral transduction of TCRs is an effective way to generate antigen-specific

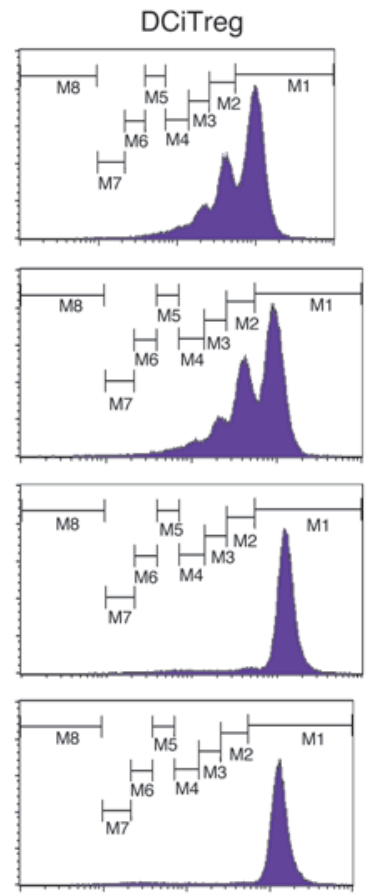

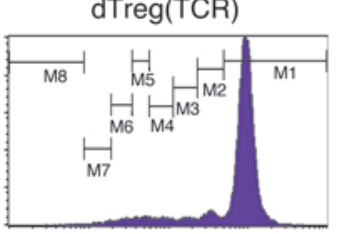
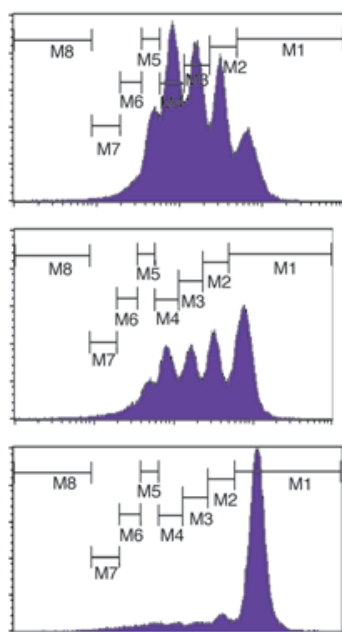
A
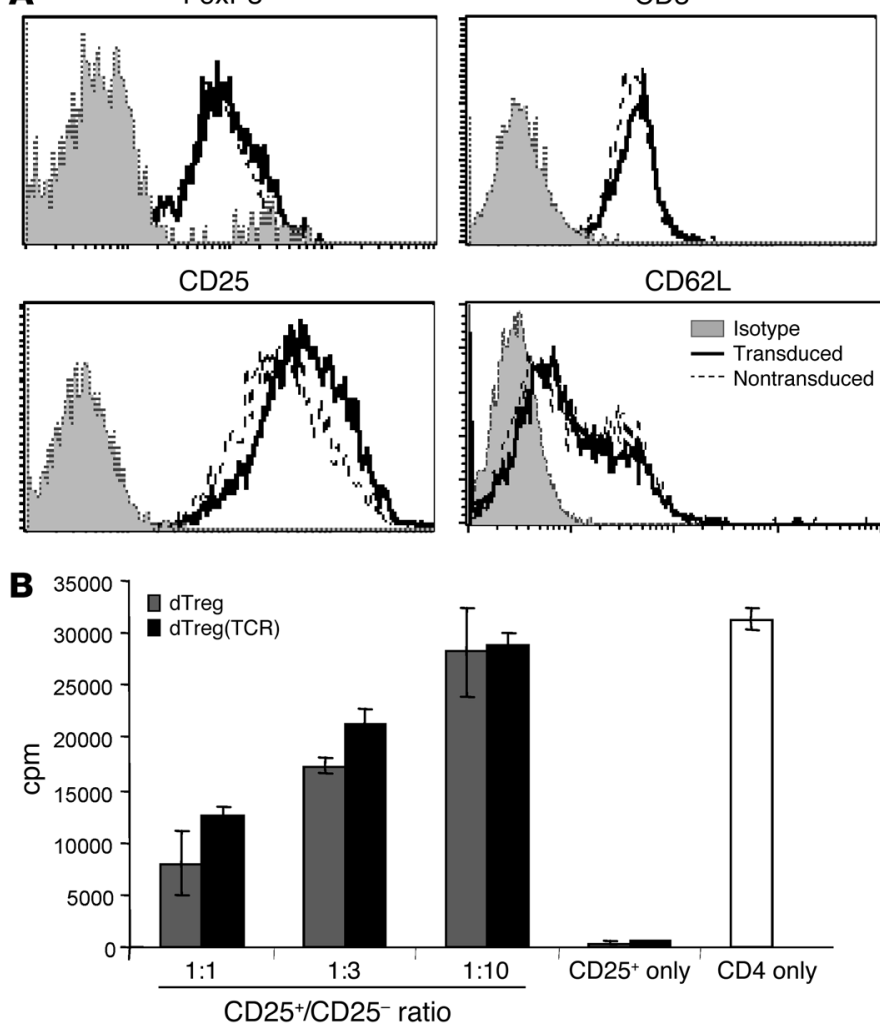

Tregs. The transgene expression was stable during long-term in vitro culture. After 3 months, the TCR-transduced Tregs retained the expression of TCR $\alpha 11.2$ and TCR $\beta 13$ (Figure 1).

TCR-transduced $C D 4^{+} \mathrm{CD} 25^{+}$Tregs showed dual allospecificity. To test the functionality of the transduced TCRs, the TCR-transduced Tregs were stimulated with mature BL/6 DCs with a range of concentrations of $\mathrm{K}^{\mathrm{d}}$ peptide, and proliferation was assessed by $\left[{ }^{3} \mathrm{H}\right]$ thymidine incorporation. TCR-transduced Tregs proliferated in response to $\mathrm{K}^{\mathrm{d}}$ peptide in a dose-dependent manner (Figure $2 \mathrm{~A}$ ). In contrast, neither nontransduced Tregs nor GFP-transduced Tregs responded to the $\mathrm{K}^{\mathrm{d}}$ peptide presented by BL/6 DCs (Figure $2 \mathrm{~A})$. The peptide dose-dependent proliferation demonstrated that the transduced TCR genes were functional.

To determine whether the TCR-transduced Tregs had both an indirect and a direct anti-H-2d specificity, the cells were labeled with CFSE and stimulated with mature DCs generated from different mouse strains. Cell proliferation was detected by CFSE dilution. The nontransduced Treg line (dTreg) that had been selected for direct allospecificity proliferated in response only to BALB/c DCs but not the other DC preparations (Figure $2 \mathrm{~B}$ ). In contrast, the TCR-transduced cells [dTreg(TCR)] with dual specificity proliferated not only in the presence of BALB/c DCs but also in response to $\mathrm{BL} / 6 \mathrm{DCs}$ in the presence of the $\mathrm{K}^{\mathrm{d}}$ peptide (Figure $2 \mathrm{~B}$ ). The superiority of the TCR transduction approach to achieve indirect allospecificity was demonstrated by comparing the proliferation of dTreg(TCR) with that of a Treg line generated and expanded with $\mathrm{K}^{\mathrm{d}}$ peptide-pulsed BL/6 DCs (DCiTregs). The response of the TCR-transduced cells to $\mathrm{K}^{\mathrm{d}}$ peptide presented by BL/6 DCs was more vigorous than the proliferation of the DCiTregs (Figure $2 \mathrm{~B}$ ). In addition, DCiTregs also proliferated in response to BL/6 DCs in the absence of $\mathrm{K}^{\mathrm{d}}$ peptide. This result further supports the idea

\section{Figure 3}

Retroviral transduction did not alter Treg phenotypes and function. (A) TCR-transduced Tregs or nontransduced Tregs were stained with anti-CD62L-FITC, anti-CD3-FITC, anti-CD25-PE, and anti-FoxP3-APC at the end of weekly stimulation. (B) CD4+ $T$ cells from BL/6 mice were cocultured either with an increasing number of TCR-transduced Tregs (black bars) or nontransduced Tregs with direct allospecificity (gray bars) in the presence of $\mathrm{T}$ cell-depleted BL/6 APCs and $1 \mu \mathrm{g} / \mathrm{ml}$ anti-CD3. CD4 ${ }^{+} \mathrm{T}$ cells (CD4 only) or Treg lines (CD25+ only) cultured with T cell-depleted splenocytes and anti-CD3 were used as controls. T cell proliferation was measured at day 3 by $\left[{ }^{3} \mathrm{H}\right]$ thymidine incorporation. Error bars represent mean $\pm \mathrm{SD}$ of experiments performed in triplicate.

that this Treg line contained autoreactive T cells, and only a small fraction of the $T$ cells had indirect allospecificity, as previously demonstrated in the human system (15). This pattern of proliferation confirmed that the transduced cells had both acquired an indirect allospecificity and had retained their direct allospecificity. Together, these results suggest that TCR transduction is a very efficient way to generate and expand Tregs with indirect allospecificity.

TCR transduction did not alter Treg properties. To address whether TCR transduction altered the phenotypic and functional properties of Tregs, the expression of cell surface markers and the suppressive capacity of TCR-transduced Tregs were compared with those of nontransduced Tregs. As shown in Figure 3A, nontransduced and TCR-transduced Tregs showed similar expression levels of Treg markers CD25 and FoxP3. Retroviral transduction of TCR did not alter the level of CD3 and CD62L expression on the Tregs. Moreover, neither in vitro suppressive activity nor proliferative properties were altered by retroviral transduction. The TCR-transduced Tregs were hyporesponsive when stimulated with anti-CD3, and the suppressive activity was equivalent to that of nontransduced Tregs (Figure 3B). These data indicated that retroviral transduction did not alter the phenotype and function of Tregs.

Activation via both transduced and endogenous TCRs can induce antigenspecific suppression. Having ascertained that retroviral transduction did not alter the suppressive capacity of the Tregs, we tested the ability of these cells to effect antigen-specific suppression. First, the TCR-transduced Tregs were cocultured with T cells with the same indirect allospecificity derived from TCR75 transgenic mice $(16,17)$. Greater than $90 \%$ suppression of proliferation was seen at a 1:1 ratio of Tregs to $\mathrm{T}$ effectors (Figure 4A). Second, the capacity of the transduced cells to effect linked suppression was examined. OT-2 T cells, specific for a peptide of OVA presented by $\mathrm{H}-2 \mathrm{~A}^{\mathrm{b}}$, were used as responder cells. The OT-2 cells were cocultured with the Tregs and BL/6 T cell-depleted APCs pulsed with both the OVA and the $\mathrm{K}^{\mathrm{d}}$ peptide. Neither nontransduced Tregs nor GFP-transduced Tregs suppressed OT-2 proliferation. However, the TCR-transduced Tregs showed suppression of OT-2 proliferation in the presence of $\mathrm{K}^{\mathrm{d}}$ peptide (Figure 4B). As shown in Figure $4 \mathrm{C}$, although modest suppression of OT- 2 proliferation was seen in the absence of the $\mathrm{K}^{\mathrm{d}}$ peptide, suppression was increased in a dose-dependent manner when the $\mathrm{K}^{\mathrm{d}}$ peptide was added to $\mathrm{BL} / 6$ T cell-depleted APCs pulsed with OVA peptide. Furthermore, the TCR-transduced Tregs retained the suppressive function mediated by their endogenous TCRs with direct allospecificity. When H-2Ad-restricted OVA-specific DO11.10 TCR-transgenic T cells 

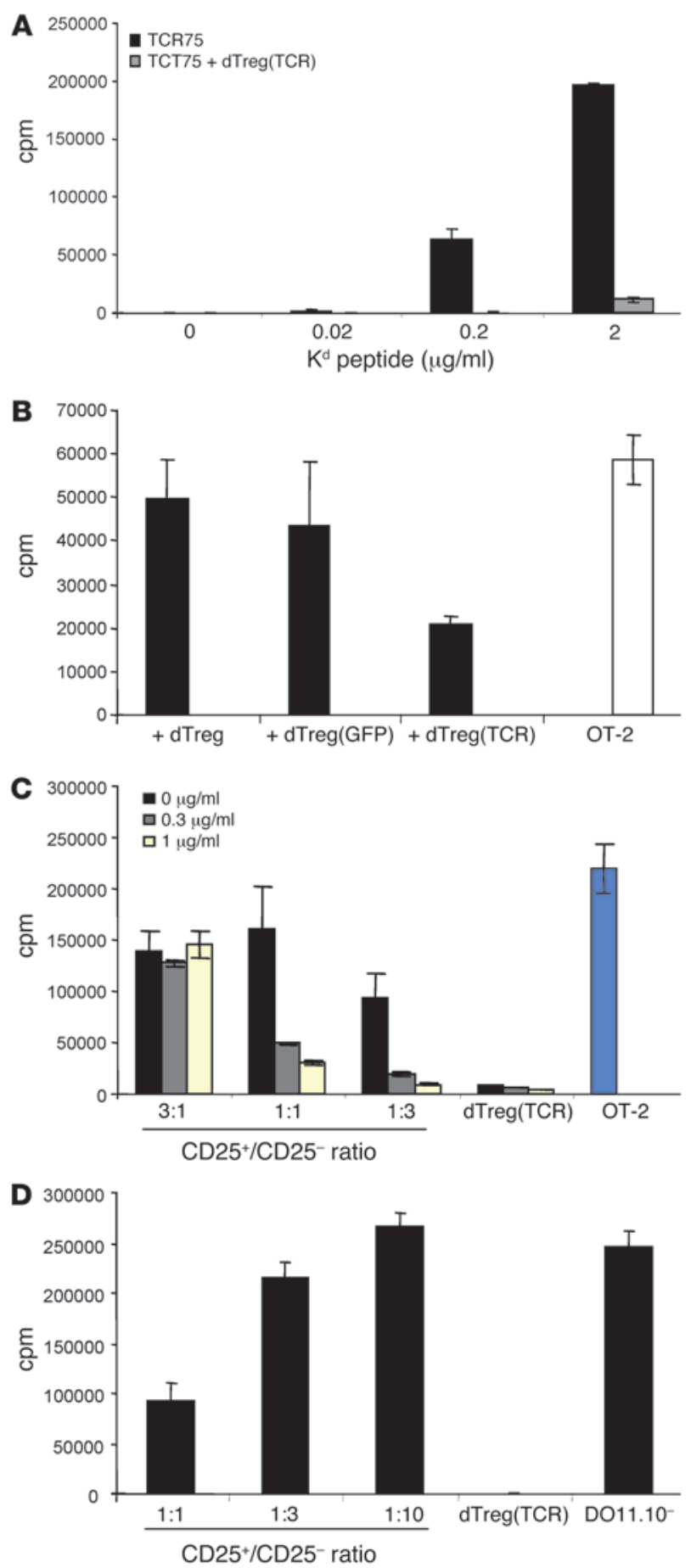

were used as responders, activation of the Tregs by $\mathrm{H}-2 \mathrm{~A}^{\mathrm{d}}$ alloantigen expressed on OVA peptide-pulsed BALB/c T cell-depleted APCs suppressed DO11.10 proliferation (Figure 4D). Together, these results demonstrate that the TCR-transduced Tregs have enhanced suppressive function following antigen-specific activation via the transduced or their endogenous TCRs. Once activated, they were able to effect linked suppression.

TCR-transduced Tregs can expand in vivo in an antigen-specific manner. It has been shown that migration of Tregs to secondary lymphoid organs is essential for controlling T cell priming in vivo (18). There-

\section{Figure 4}

Alloantigen-specific TCR-transduced Tregs can suppress CD4+CD25responders in an antigen-specific manner. (A) TCR75 TCR-transgenic CD4+ $T$ cells were either cultured alone (black bars; TCR75) or cocultured with TCR-transduced Tregs [gray bars; TCR75 + dTreg(TCR)] in a 1:1 ratio in the presence of T cell-depleted BL/6 APCs and different amounts of $\mathrm{K}^{\mathrm{d}}$ peptides. (B) OT-2 TCR-transgenic CD4+ $\mathrm{T}$ cells were cocultured with direct specific Treg lines, GFP-transduced Tregs, or TCR-transduced Tregs in the presence of T cell-depleted BL/6 APCs plus $1.0 \mu \mathrm{g} / \mathrm{ml} \mathrm{Kd}$ peptide and $0.5 \mu \mathrm{g} / \mathrm{ml}$ OVA peptide. OT-2 cells cultured without Tregs (white bar) were used as controls. (C) OT-2 TCRtransgenic $\mathrm{CD}^{+} \mathrm{T}$ cells were cocultured with increasing numbers of TCR-transduced Tregs in the presence of T cell-depleted BL/6 APCs plus different amounts of $\mathrm{K}^{\mathrm{d}}$ peptides $(0,0.3,1.0 \mu \mathrm{g} / \mathrm{ml})$ and $0.5 \mu \mathrm{g} / \mathrm{ml}$ OVA peptide. OT-2 cultured without Tregs (blue bar) were used as controls. (D) DO11.10 TCR-transgenic CD4 ${ }^{+} \mathrm{T}$ cells were cocultured with TCR-transduced Tregs in the presence of T cell-depleted BALB/C APCs in the presence of $0.5 \mu \mathrm{g} / \mathrm{ml}$ OVA peptide. DO11.10 culture without Tregs (DO11.10) was used as control. T cell proliferation was measured at day 3 by $\left[{ }^{3} \mathrm{H}\right]$ thymidine incorporation. Error bars represent mean \pm SD of experiments performed in triplicate.

fore, the ability of the TCR-transduced Tregs to migrate to the secondary lymphoid organs and to proliferate in response to their cognate antigen was tested. CFSE-labeled TCR-transduced Tregs were injected into either $\mathrm{BL} / 6$ or $\mathrm{BL} / 6 . \mathrm{K}^{\mathrm{d}}$ mice. At day 3 after transfer, the mice were sacrificed and examined for CFSE dilution. As shown in Figure 5, CFSE-positive cells were detected in both lymph nodes and spleen, suggesting that they retained their capacity to home to secondary lymphoid organs. In addition, the transferred cells proliferated extensively in vivo in $\mathrm{BL} / 6 . \mathrm{K}^{\mathrm{d}}$ mice, in which the $\mathrm{K}^{\mathrm{d}}$ molecule is presented both directly and indirectly. Minimal proliferation was seen in BL/6 mice. Furthermore, the expansion occurred preferentially at the site of antigenic challenge. When the CFSE-labeled TCR-transduced Tregs were transferred into BL/6 mice that had received a BL/6. $\mathrm{K}^{\mathrm{d}}$ skin graft, proliferation of Tregs was not detected in the spleen and mesenteric lymph nodes, but the cells proliferated and expanded in the graft-draining lymph node (Figure 6). Furthermore, no cell division was detected in the animals carrying a CBA skin graft even in the graft-draining lymph nodes, confirming the antigen specificity of the injected cells.

TCR-transduced Tregs can control indirect alloresponses in vivo. The ultimate goal of this study was to use Tregs with allospecificity to induce transplantation tolerance in a fully mismatched strain combination. First, the in vivo specificity and suppressive function of TCRtransduced Tregs was evaluated in a skin transplant model. Treg lines were injected into BL $/ 6$ recipients 1 day before transplantation of a BL/6.K $\mathrm{K}^{\mathrm{d}}$ skin graft. The median survival time (MST) of BL/ $6 . \mathrm{K}^{\mathrm{d}}$ skin grafts on $\mathrm{BL} / 6$ mice was 15 days (Figure 7 ). Intravenous injection of TCR-transduced Tregs with both direct and indirect allospecificities significantly prolonged $\mathrm{BL} / 6 . \mathrm{K}^{\mathrm{d}}$ graft survival (MST, 24 days), while adoptive transfer of nontransduced Tregs - which lacked indirect anti- $\mathrm{K}^{\mathrm{d}}$ specificity but had anti-BALB/c specificity and were unable to recognize intact $\mathrm{K}^{\mathrm{d}}$ molecules because of their CD4 nature - did not delay graft rejection (MST, 15 days) [no cells: $P<0.01$; dTreg: $P<0.01$; autoTreg: $P<0.05$; dTreg(TCR)-treated group versus other groups]. In addition, transfer of an autoreactive Treg line generated by stimulation with autologous BL/6 DCs did not prolong graft survival. These data suggest that TCR-transduced Tregs specific for the alloantigen expressed by the transplant are effective in controlling indirect alloresponses in vivo and also 


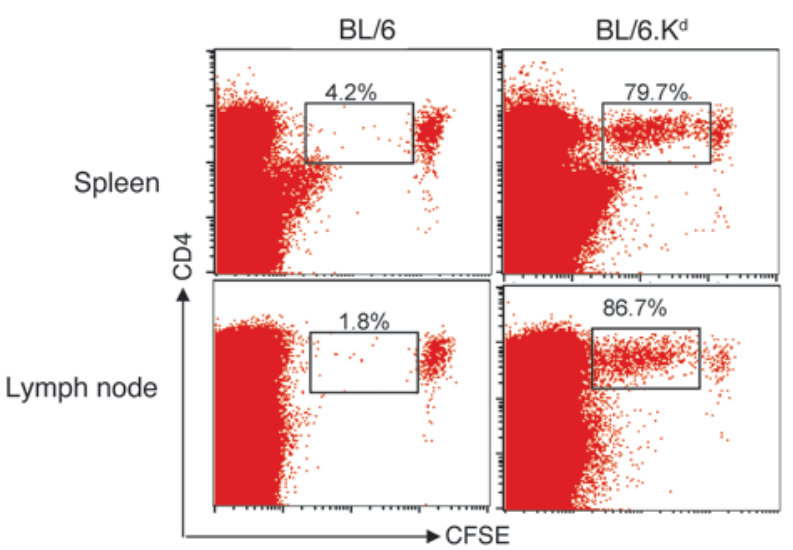

demonstrate the relevance of antigen specificity in the effectiveness of the in vivo suppressive function.

TCR-transduced Tregs in combination with rapamycin and anti-CD8 antibody can induce indefinite graft survival in fully immunocompetent mice. Although there are numerous studies showing experimental transplantation tolerance induced by Tregs, many were based on adoptive transfer of both Tregs and $\mathrm{T}$ effectors in lymphopenic mice or across minor mismatches. The data presented in Figure 7 clearly demonstrate that TCR-transduced Tregs have the capacity to inhibit an indirect alloresponse in fully immunocompetent recipients. However, long-term graft survival was not achieved in the $\mathrm{BL} / 6 . \mathrm{K}^{\mathrm{d}}$ skin transplant model. The induction of transplantation tolerance was investigated in a heart transplant model in a haplotype-mismatched strain combination. It has been suggested that Treg treatment alone may not be sufficient for tolerance induction, and trimming of the alloreactive $T$ cell pool may be necessary for Tregs to be effective (19). Furthermore, it has been shown that Tregs are less effective in controlling CD8 responses than CD4 responses in vivo. However, in $\mathrm{Rag}^{-1-}$ mice, Tregs that prevented graft rejection mediated by $\mathrm{CD} 4^{+} \mathrm{T}$ cells only delayed graft rejection mediated by $\mathrm{CD}^{+} \mathrm{T}$ cells, presumably due to linked suppression (20). Besides, it has been shown that independent targeting of $\mathrm{CD}^{+} \mathrm{T}$ cells can convert ineffective into effective therapeutic protocols in several transplant models (21). In light of these observations, a combination of depleting anti-CD8 antibody and Tregs was tested using a vascularized heart transplant model.

\section{Figure 5}

TCR-transduced Tregs can migrate to secondary lymphoid organs and expand in vivo in the presence of specific antigen. TCR-transduced Tregs $\left(5 \times 10^{6}\right)$ were labeled with $1 \mu \mathrm{M}$ CFSE and were injected i.v. into either $\mathrm{BL} / 6$ or $\mathrm{BL} / 6 . \mathrm{K}^{\mathrm{d}}$ mice. Three days later, mice were sacrificed. Lymph nodes and spleens were harvested. Cells from lymph nodes and spleen were stained with anti-CD4-APC. In vivo proliferation of the cells was analyzed by flow cytometric analysis of CFSE dilutions. CFSE-positive cells were gated for analysis. The percentage of CFSE-positive cells in the gated region is indicated.
$\mathrm{BL} / 6$ mice received a $\mathrm{B} 6 \mathrm{D} 2 \mathrm{~F} 1$ heart transplant on day 0 and a combination of anti-CD8 antibody $(250 \mu \mathrm{g}$ i.p. on days -1 and 1$)$ with either Tregs with only a direct anti-H-2d specificity or the transduced cells with both direct and indirect specificity for $\mathrm{H}-2^{\mathrm{d}}$ alloantigens (i.v. on days $-1,7,14$, and 21 ). The injection of Tregs with direct allospecificity led to a slight prolongation of graft survival, but heart transplants were still rejected, with an MST of 34 days (MST of 25.5 days for anti-CD8 treatment), in agreement with the previous findings that controlling direct pathway alone cannot provide sufficient graft protection to induce tolerance (22). In contrast, the injection of the TCR-transduced Tregs, which had direct and indirect allospecificity, led to long-term survival of the heart grafts (MST, > 150 days) (Figure $8 \mathrm{~A}$ ), suggesting that regulation of both pathways together is important for tolerance induction in this strain combination. $\mathrm{CD}^{+} \mathrm{T}$ cell counts had returned to normal levels when the grafted animals were analyzed at day 100 (data not shown), and the long-term-surviving hearts showed normal myocardial architecture and no significant intimal proliferation (Figure 8B).

The efficacy of combining allospecific TCR-transduced Tregs with alloreactive $\mathrm{T}$ effector cell depletion was further tested in a more challenging strain combination, with transplantation of fully mismatched $\mathrm{BALB} / \mathrm{c}$ hearts into $\mathrm{BL} / 6$ mice. However, it has been shown that adoptive transfer of Tregs together with $\mathrm{CD}^{+}$effector cells, even at a 1:1 ratio, cannot control CD4-mediated BALB/c rejection in $\mathrm{BL} / 6 \mathrm{Rag}^{-1}$ recipients (20). Thus, a short course of rapa-

\section{Figure 6}

TCR-transduced Tregs expanded at the site of antigenic challenge. TCR-transduced Tregs $\left(5 \times 10^{6}\right)$ were labeled with $1 \mu \mathrm{M}$ CFSE and were injected i.v. into BL/6 mice. One day after transfer, the mice received skin grafts from either $\mathrm{BL} / 6 . \mathrm{K}^{\mathrm{d}}$ donors or CBA donors. Mice were sacrificed at day 12 after transplantation. Graft draining lymph nodes, mesenteric lymph nodes, and spleens were harvested. Cells from different lymph nodes and spleens were stained with anti-CD4-APC. In vivo proliferation of Tregs was analyzed by flow cytometric analysis of CFSE dilutions. CFSE-positive cells were gated for analysis.

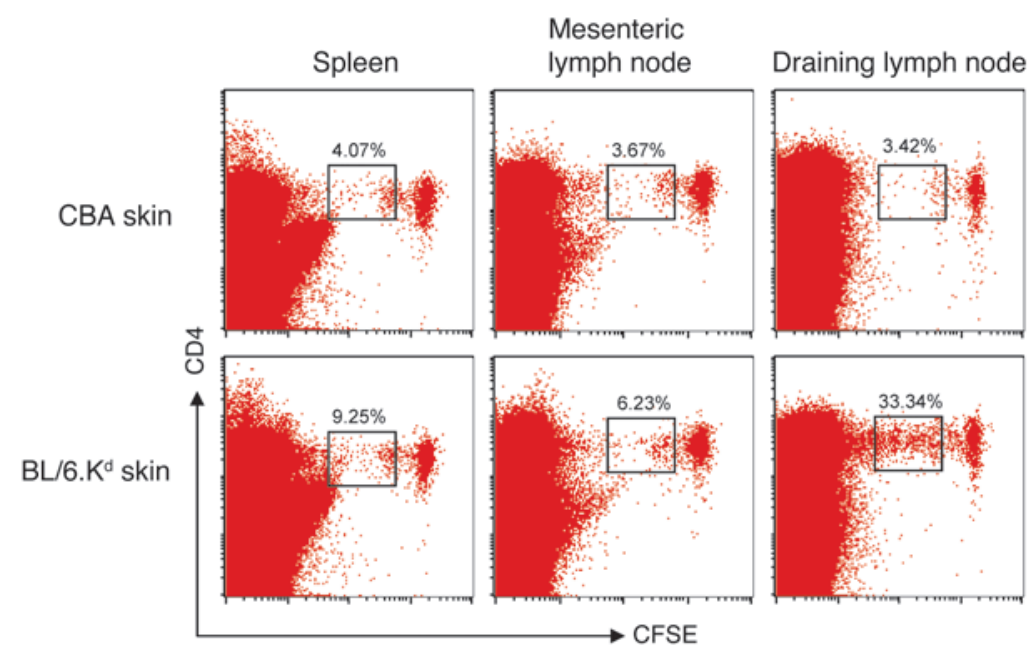




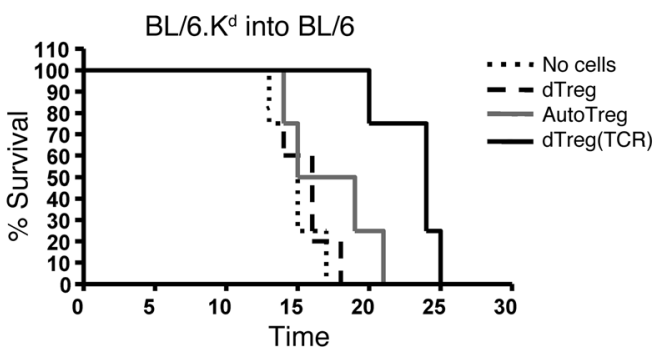

mycin ( $1 \mathrm{mg} / \mathrm{kg} / \mathrm{d}$ i.p. daily on days -1 to 13$)$ was added to the treatment. This immunosuppressive agent can markedly reduce the alloreactive $\mathrm{T}$ cell pool without compromising the function of Tregs (23-26). As shown in Figure 9A, anti-CD8 antibody plus rapamycin alone prolonged graft survival compared with anti-CD8 treatment alone (MST, 59 days). When TCR-transduced Tregs with both direct and indirect allospecificities were included in the protocol, indefinite survival was observed (MST, >150 days). Furthermore, in this strain and treatment combination, addition of Treg lines with only direct allospecificity also induced prolonged survival of heart graft (MST, 107 days). However, differences were observed in the histology of the hearts from the mice receiving either the Treg line with dual specificity or with direct specificity only. The long-term-surviving hearts from animals receiving TCR-transduced Tregs with both direct and indirect allospecificities showed normal myocardial architecture, with cardiac muscle cells arranged in an orderly manner (Figure 9E) as well as normal cardiomyocytes and vasculature (Figure 9F, yellow area) and less neointimal thickening (Figure 9G). In contrast, grafts from animals that received Treg lines with only direct allospecificity had advanced vascular lesions, the formation of neointimal thickening (Figure 9D), abnormal myocardial architecture (Figure 9B), and the replacement of some cardiomyocytes by collagen and fibrous tissues (Figure 9C, red area) close to normal cardiomyocytes (Figure 9C, yellow area). Moreover, heart grafts of animals that received TCR-transduced Tregs with both direct and indirect allospecificities showed lower mean luminal occlusion $(10.07 \% \pm 2.30 \%, n=61$ vessel cross sections) compared with those that received Treg lines with direct allospecificity $(29.52 \% \pm 3.81 \%$, $n=62$ vessel cross sections) (Figure $9 \mathrm{H}$ ). In vitro analysis failed to detect any differences in the $\mathrm{T}$ cell responses to BALB/c DCs or toward $\mathrm{K}^{\mathrm{d}}$ peptide between long-term survivors and mice that had rejected the transplant in mixed lymphocyte reactions (data not shown). Together, our data demonstrate that long-term graft survival can be achieved even in a stringent allograft model by combining adoptive therapy with dual-specificity Tregs and treatment with anti-CD8 antibody and short-term rapamycin.

\section{Figure 8}

TCR-transduced Tregs with both direct and indirect specificity are required to induce long-term graft survival in fully immunocompetent mice. (A) B6D2F1 hearts were transplanted into BL/6 recipients. Shortterm CD8 T cell depletion was achieved by i.p. injection of $250 \mathrm{mg}$ anti-CD8 at days -1 and 1. TCR-transduced direct allospecific Tregs $\left(5 \times 10^{6} ; n=4\right)$ or nontransduced Tregs with direct allospecificity $(n=6)$ were injected i.v. at days $-1,7,14$, and 21 into BL/6 mice. WT $\mathrm{BL} / 6$ recipients with anti-CD8 without Tregs served as controls $(n=6)$. (B) Heart graft harvested at day 100 after transplantation were fixed and stained with H\&E staining and elastin/van Gieson staining (original magnification, $\times 400$ ).

\section{Figure 7}

TCR-transduced Tregs prolonged $\mathrm{BL} / 6 . \mathrm{K}^{\mathrm{d}}$ skin graft survival in fully immunocompetent mice. TCR-transduced Tregs $\left(5 \times 10^{6} ; n=4\right)$, nontransduced Tregs with direct allospecificity $(n=5)$, or Tregs expanded with autologous BL/6 DCs (AutoTreg; $n=4$ ) were injected i.v. into BL/6 mice. One day after transfer, the mice received skin graft from BL/6. $K^{\mathrm{d}}$ donors. WT BL/6 recipients $(n=4)$ of grafted BL/6.K $\mathrm{K}^{\mathrm{d}}$ skin without Treg injection served as controls.

\section{Discussion}

It is well established that MHC alloantigens are recognized by 2 pathways, known as direct and indirect. Although both pathways can independently effect transplant rejection in rodent models, it is likely that the high-frequency direct pathway is the major driver of acute early rejection and that the lower-frequency indirect pathway plays a more important role at later time points (27). In this study, we have engineered naturally occurring Tregs to create a population capable of targeting both types of alloresponse. These cells, selected for direct allospecificity and retrovirally transduced to create an indirect allospecificity, retained their suppressive potency and mediated linked suppression in vitro, trafficked to lymph node draining sites of antigen availability, and prolonged transplant survival in vivo. Furthermore, adoptive therapy with the Treg line with dual specificity was effectively combined with treatment with either anti-CD8 antibody alone or the combination of anti-CD8 and rapamycin to induce long-term survival of semi-mismatched and fully MHC-mismatched grafts. However, in the latter strain and treatment combination, Tregs with only direct allospecificity were only slightly less effective in prolonging graft

A
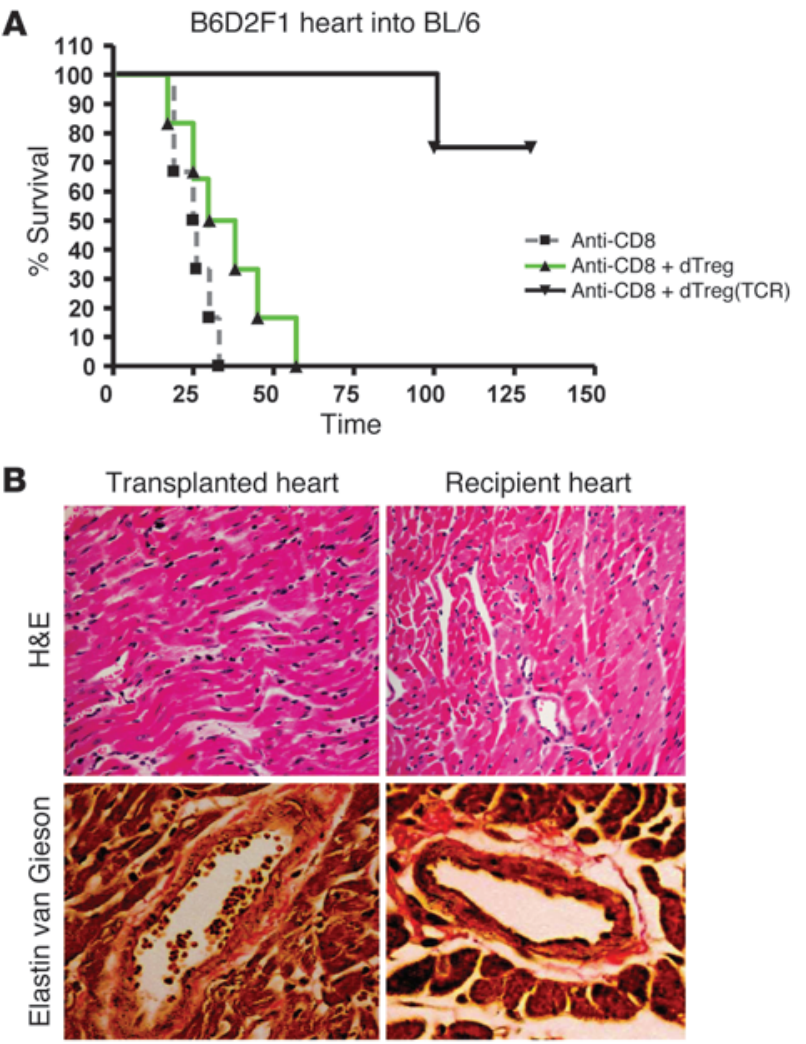
A
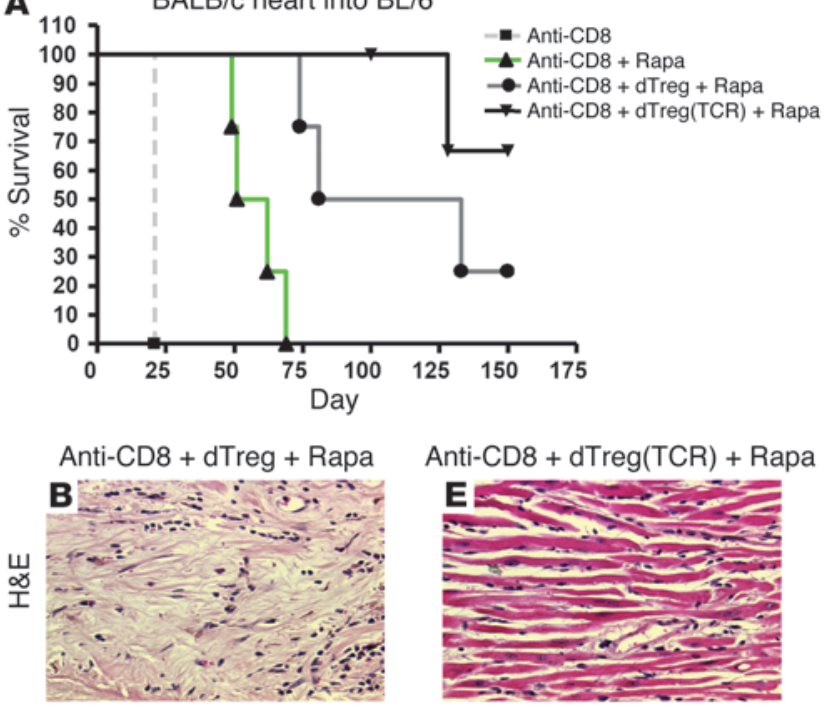

Anti-CD8 + dTreg(TCR) + Rapa
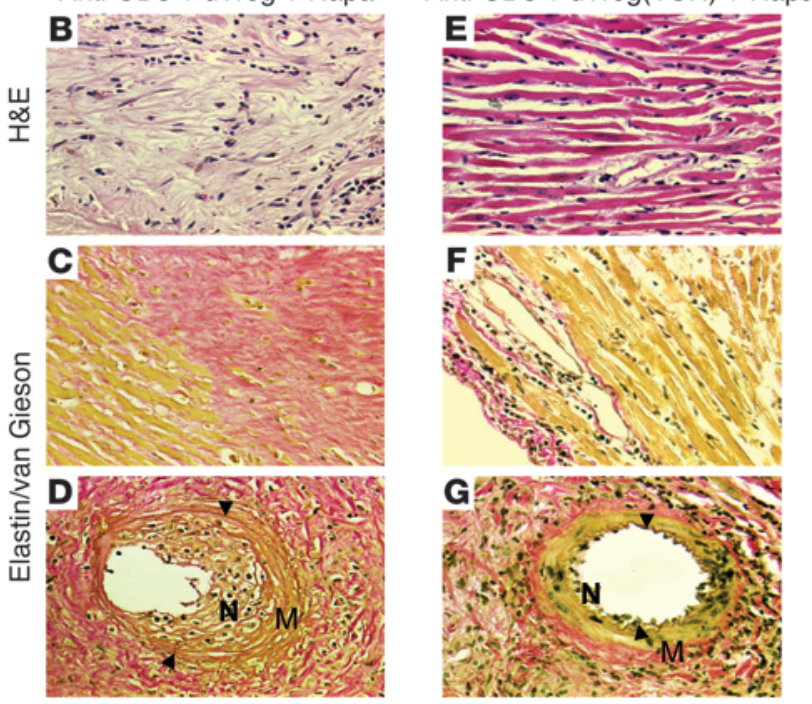

\section{H}

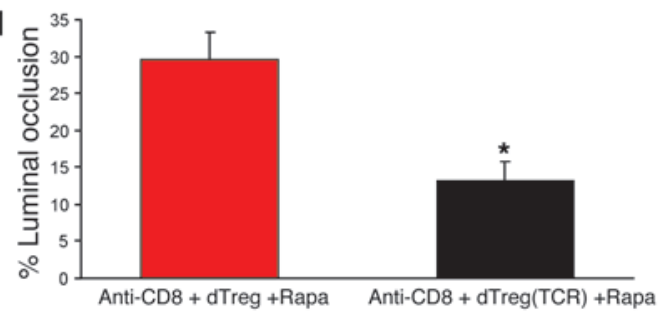

survival. However, a striking difference was seen in the histological appearance of the long-surviving heart grafts. The hearts that had received the Tregs with dual specificity had normal myocardial architecture; in marked contrast, the hearts from mice injected with Treg lines with only direct allospecificity showed vascular lesions, the formation of neointimal thickening, and abnormal myocardial architecture.

The potential of TCR gene transfer for antigen-specific immunotherapy has been demonstrated recently in cancer studies (28). This is the first report to our knowledge of conferring a desired specificity on Tregs by TCR gene transduction. This maneuver had several benefits. First, it allowed for a massive enrichment of cells with the desired specificity. Earlier attempts at selecting Tregs with indirect allospecificity in murine and human systems were much less efficient. Using human cells and an HLA-DR1:A2 tetramer as the readout, we were able to detect $9 \%$ tetramer-positive cells after repeated in vitro stimulation with allopeptide-pulsed autologous DCs. Presumably, the tetramer-negative cells were autoreactive

\section{Figure 9}

TCR-transduced Treg therapy in combination with other treatments can induce tolerance to fully mismatched heart transplant in fully immunocompetent mice. (A) BALB/c hearts were transplanted into the $\mathrm{BL} / 6$ recipients. Short-term $\mathrm{CD} 8^{+} \mathrm{T}$ cell depletion was achieved by i.p. injection of $250 \mathrm{mg}$ anti-CD8 at days -1 and 1. Rapamycin (Rapa) treatment was given i.p. between days -1 and $14(1 \mathrm{mg} / \mathrm{kg} / \mathrm{d})$. TCRtransduced Tregs $\left(1 \times 10^{7} ; n=4\right)$ and nontransduced direct allospecific Tregs $(n=4)$ were injected i.v. at days $-1,7,14$, and 21 into BL/6 mice. WT BL/6 recipients with anti-CD8 $(n=3)$ or rapamycin plus anti-CD8 $(n=3)$ without Tregs served as controls. (B-H) Heart grafts harvested at day 150 after transplantation were fixed and stained with H\&E (B and $\mathbf{E}$ ) and elastin/van Gieson staining (C, D, F, and G) (original magnification, $\times 400$ ). Arrowheads indicate internal elastic lamina. $N$, neointima; M, media of arteries. (H) Images were analyzed quantitatively for luminal occlusion, and a total of 123 vessels were analyzed. Data represent the mean value \pm SEM. ${ }^{*} P<0.0001$ between anti-CD8 + dTreg + Rapa and anti-CD8 + dTreg(TCR) + Rapa groups.

(15). In contrast, after TCR transduction and subsequent antigen stimulation, over $50 \%$ of the Tregs expressed the relevant receptor. This approach can circumvent the laborious and time-consuming selection as well as culture procedures needed for in vitro expansion of antigen-specific Tregs. An alternative method was explored by Masteller et al. using beads coated with recombinant MHC class II peptide complexes and anti-CD28 antibody (MHC II:peptide/ anti-CD28 beads) to expand antigen-specific Tregs. Although this approach could avoid expansion of autoreactive cells, it has raised another issue. Tregs expanded in this way were not as efficient as Tregs expanded from TCR-transgenic mice in controlling autoimmune diabetes. The lack of efficacy may have been due to the expansion of Tregs with low antigen affinity due to the high ligand density when coated beads were used (29). TCR transfer studies have demonstrated that transduction of high-avidity TCRs into $\mathrm{T}$ cells is accompanied by the maintenance of the avidity of the parent $T$ cell $(30,31)$, suggesting that by transducing high-affinity TCRs, the problem of selecting low-avidity Tregs can be avoided and the functional efficacy of the T cells can be further improved.

Second, the generation of these highly enriched Tregs with defined allospecificity provided the opportunity to address a key question concerning the clinical application of this population of Tregs in transplantation, namely, is specificity for cognate antigen an advantage? Several experimental and clinical studies have demonstrated a benefit from using polyclonal Tregs, particularly in the inhibition of GVHD (2, 32-34). Given the phenomenon of linked suppression, it could be argued that the autoantigen specificity of these cells is sufficient to achieve the desired effect on the basis of the hypothesis that recipient DCs that are presenting donor MHC alloantigen in peptide form will simultaneously be presenting autoantigenic peptides. For inhibition of direct alloresponses, the frequency of cells that cross-react with MHC alloantigens may be high enough to target injected cells to sites of alloreactivity in vivo. The clear implications of the data presented here are that specificity for donor alloantigens confers a substantial advantage over autoreactive populations. The finding that offers an explanation for this observation is that the TCR-transduced cells trafficked to secondary lymphoid organs, and divided in the lymph node draining the site where alloantigen was available. When polyclonal cells are injected, they can be assumed to distribute themselves throughout all lymphoid tissues, leading to a major dilutional effect. In a previous study, we reported that a Treg line, selected for indirect allo- 
specificity by repetitive alloantigen stimulation, could be detected in the lymph node draining an accepted skin graft carrying the relevant antigen and in the graft itself (13). These findings suggest that antigen-specific cells are substantially more efficient in effecting suppression and may be long lived in vivo after adoptive transfer. Furthermore, the finding that injection of Tregs with both direct and indirect allospecificities in both strain combinations studied here induced long-term graft protection has important therapeutic implications for Treg-based therapies. A recent report has provided evidence that Tregs with direct allospecificity only cannot protect against chronic rejection (in a DBA-into-BL/ 6 combination) and that for optimal efficacy in preventing graft rejection, Tregs with both direct and indirect allospecificities are necessary (22). In line with these findings, we demonstrated that Tregs with both direct and indirect specificity showed superior protection compared with Tregs with direct specificity in the semi-mismatched heart transplant model. In the fully mismatched strain combination, Tregs with direct specificity were also able to induce indefinite survival in some animals. However, histological analysis of the heart grafts from mice treated with Tregs that only had direct anti-donor allospecificity revealed clear signs of rejection. It is interesting to consider the possible significance of the dual, direct and indirect, allospecificity of the dTreg(TCR) cells. There are 2 key considerations: first, which cells in which strain combination would be expected to express the ligands recognized by both TCR specificities; and second, how long donor MHC class II is expressed after transplantation to allow stimulation of the dTregs. In answer to the first question, in the B6D2F1-into-BL/6 combination, the major cell expressing both ligands would be the donor DC due to constitutive expression of $\mathrm{H}-2^{\mathrm{d}}$ class II and constitutive processing of $\mathrm{K}^{\mathrm{d}}$ and subsequent presentation by $\mathrm{H}-2 \mathrm{~A}^{\mathrm{b}}$. In this strain combination, the dual stimulation of the dTreg(TCR) cells may have augmented their potency and consequent efficacy. In contrast, in the fully mismatched combination, the direct stimulus would have come from the donor and the indirect stimulus from the recipient cells. Although there is relatively little class II expression on the mouse heart, the partial efficacy of the dTregs in the BALB/c-into-BL/6 combination may reflect their accumulation in the graft itself and ongoing activation by persisting low levels of $\mathrm{H}-2^{\mathrm{d}}$ class II.

The combined studies of Turka and Strom in the late 1990s highlighted the requirement for deletion of substantial numbers of $\mathrm{T}$ cells with direct alloreactivity if tolerance is to be achieved across an MHC incompatibility (35). This reflects the simple fact that the size of the alloreactive $\mathrm{T}$ cell repertoire is too large to be manageable, for example, by regulation, unless this repertoire is diminished. With this in mind, we combined the adoptive therapy of engineered Tregs with 2 adjunctive treatments: a depleting anti-CD8 monoclonal antibody to temporarily reduce the CD8 response and short-course rapamycin. It should be emphasized that both of these measures were temporary; $\mathrm{CD}^{+} \mathrm{T}$ cell numbers recovered over the weeks after the transplants were performed, and rapamycin was only given for the first 2 weeks. Importantly, rapamycin has been shown by Strom and colleagues to allow $\mathrm{T}$ cell deletion, due to IL-2-mediated activation-induced cell death while preserving Tregs in vivo (19).

Taken together, our results suggest that the strategy of engineering Tregs to have allospecificity for donor antigens and combining the administration of these cells with other immunosuppressive approaches that do not undermine the Treg-mediated effects has clinical potential. Furthermore, this approach should also be applicable to autoimmune disease states where the autoantigens are known.

\section{Methods}

Mice, culture media, reagents, and antibodies. $\mathrm{BL} / 6\left(\mathrm{H}-2^{\mathrm{b}}\right), \mathrm{BALB} / \mathrm{c}\left(\mathrm{H}-2^{\mathrm{d}}\right), \mathrm{BL} / 6$ $\times$ DBA2 $\mathrm{F}_{1}\left(\mathrm{H}-2^{\mathrm{b}} \times \mathrm{H}-2^{\mathrm{d}} ; \mathrm{B} 6 \mathrm{D} 2 \mathrm{~F} 1\right)$, and CBA $\left(\mathrm{H}-2^{\mathrm{k}}\right)$ mice aged $6-8$ weeks old were purchased from Charles River Laboratories. OT-2, DO11.10, BL/6.K $\mathrm{K}^{\mathrm{d}}$ (BL/6 transgenic for $\mathrm{K}^{\mathrm{d}}$ ), and TCR75 (TCR-transgenic mice recognizing $\mathrm{K}^{\mathrm{d}}$ peptide:H-2 $\left.\mathrm{A}^{\mathrm{b}}\right)(17)$ mice were bred and maintained in the Biological Services Unit (New Hunt House) of King's College London. DO11.10 mice were a gift from Domenico Spina (King's College London). All animals experimental procedures were approved by UK Home Office. RPMI 1640 medium supplemented with L-glutamine (Gibco, Invitrogen), penicillin/streptomycin (Gibco, Invitrogen), and 10\% (v/v) FCS (Harlan) was used for all in vitro assays. For cell purification and washing steps, RPMI 1640 medium supplemented with $2 \%$ FCS was used. Anti-CD4-APC (clone CT-CD4) was obtained from Caltag, Invitrogen. Anti-CD4-FITC (clone GK1.4), anti-CD25-PE (clone PC61), anti-TCRV $\alpha 11.1 / 2-P E$ (clone RR8-1), and anti-TCRV $\beta 13-$ FITC (clone MR12-3) were purchased from BD Biosciences - Pharmingen. Anti-FoxP3-APC (clone FJK-16s) was obtained from eBioscience.

Preparation of mouse $C D 4^{+} \mathrm{CD} 25^{-}$and $C D 4^{+} \mathrm{CD} 25^{+} \mathrm{T}$ cells. Spleen and lymph nodes were harvested from $\mathrm{BL} / 6$ mice. $\mathrm{CD}^{+} \mathrm{T}$ cells were prepared using a CD4 Negative Isolation Kit (Dynal, Invitrogen). The purified CD4 ${ }^{+}$ $\mathrm{T}$ cells were then incubated with biotinylated anti-CD25 antibody (clone 7D4; BD Biosciences - Pharmingen) for 20 minutes in ice, followed by incubation with streptavidin microbeads (Miltenyi Biotec) for 15 minutes at $10^{\circ} \mathrm{C} . \mathrm{CD}^{+} \mathrm{CD} 25^{-} \mathrm{T}$ cells were separated from $\mathrm{CD} 4^{+} \mathrm{CD} 25^{+} \mathrm{T}$ cells by passing through a MACS column. The unbound fraction contained the $\mathrm{CD} 4^{+} \mathrm{CD} 25^{-} \mathrm{T}$ cells. $\mathrm{CD} 4^{+} \mathrm{CD} 25^{+} \mathrm{T}$ cells were eluted from the column. The purity of the cells was checked by flow cytometry.

Generation of DCs. The protocol of Steinmen et al. was used to generate DCs from bone marrow (36). Briefly, bone marrow cells $\left(5 \times 10^{5} / \mathrm{ml}\right)$ were treated with a mixture of anti-CD8, anti-CD4, anti-B220, and anti-MHC class II supernatants (YTS169, YTS191, RA34.5, M5/114) for 30 minutes. After antibody treatment, the cells were washed and incubated with goat anti-rat IgG Dynal beads (Invitrogen) for 30 minutes. Unbound cells enriched with precursor cells were cultured with 10\% FCS RPMI 1640 containing $5 \%(\mathrm{v} / \mathrm{v})$ supernatant from a GM-CSF-secreting transfected cell line. On days 2 and 4, nonadherent cells were removed. Fresh medium with GM-CSF was added to the adherent fraction for continuing culture. Cells were used from day 6.

Generation of $\mathrm{CD}^{+} \mathrm{CD} 25^{+}$Treg lines. To expand alloantigen-specific $\mathrm{CD} 4^{+}$ $\mathrm{CD} 25^{+}$Tregs with direct specificity, the cells $\left(2 \times 10^{6}\right.$ cells/well $)$ were stimulated weekly with immature BALB/c DCs $\left(5 \times 10^{5} /\right.$ well $)$ in the presence of 10 $\mathrm{U} / \mathrm{ml}$ IL-2 in a 24-well plate. To expand Tregs with indirect allospecificity, autologous $\mathrm{BL} / 6$ DCs pulsed with the $\mathrm{K}^{\mathrm{d}}$ peptide were used in the stimulation. Autoreactive Treg lines were generated by repeated stimulation with autologous BL/6 DCs. To maintain the TCR-transduced Tregs, $2 \times 10^{6} /$ well Tregs were stimulated with $\mathrm{K}_{54-68}$ peptide-pulsed BL/6 DCs $\left(5 \times 10^{5} /\right.$ well).

Preparation of retroviral constructs and virus production. Indirect allospecific TCR $\alpha$ chain cDNA (V $\alpha 11.2)$ and TCR $\beta$ chain cDNA (V $\beta 13)$ were PCR amplified using template cDNA prepared from RNA of BL/6.Rag - $^{-T C R} 34$ splenocytes (16). Primer sequences were as follows: for TCR $\alpha$ chain, 5'-ATGCGCGGCCGCAAGACAACCAGCGATTGGAC-3' (forward) and 5'-ATGCGAATTCCTCTGTCAGTCTTGCAG-3' (reverse); for TCR $\beta$ chain, 5'-ATGCGCGGCCGCATGGGCACCAGGCTTCTTGGC-3' (forward) and 5'-TACGTAGAATTCACATCTGGCTTCATGAGTTCTTTCTTTTGAC-3' (reverse) (underlining indicates the restriction site). A NotI site was introduced in the forward primer, and an EcoRI site was introduced in the 
reverse primer. The fragments were confirmed by sequencing and cloned into pMP71GPRE retroviral vector between the NotI and EcoRI sites upstream of the PRE sequence.

Production of retroviral supernatants and retroviral transduction. To prepare retroviral supernatant, the TCR $\alpha$ and TCR $\beta$ constructs were transfected into Phoenix-Eco packaging cells (37) by $\mathrm{CaPO}_{4}$ transfection. Supernatant was collected on day 2 after transfection. For retroviral transduction, $\mathrm{T}$ cells were first activated with DCs and anti-CD3 $(1 \mu \mathrm{g} / \mathrm{ml})$ for 48 hours. The activated cells were then transferred to a RetroNectin-coated (Takara) 24 -well plate $\left(2 \times 10^{6}\right.$ to $3 \times 10^{6} /$ well $)$ with $50 \%(\mathrm{v} / \mathrm{v})$ retroviral supernatant supplemented with $10 \mathrm{U} / \mathrm{ml} \mathrm{IL}-2$ and cultured at $37^{\circ} \mathrm{C}$ for 24 hours. Supernatants were removed, and the cells were cultured in fresh medium supplemented with IL-2.

$T$ cell proliferation assays. For in vitro proliferation assay, Tregs $\left(5 \times 10^{4}\right.$ cells/well) were stimulated with $\gamma$-irradiated (30 Gy) mature DCs $\left(5 \times 10^{3}\right.$ cells/well) in a 96-well plate. For suppression experiments where $5 \times 10^{4}$ cells/well OT-2 or DO11.10 were used as responders, $0.2 \mu \mathrm{g} / \mathrm{ml}$ OVA peptide $\left(\mathrm{OVA}_{323-334}\right)$ and $\mathrm{T}$ cell-depleted splenocytes $\left(1 \times 10^{5}\right.$ cells/well $)$ were used for cell stimulation. Proliferation was assessed by $\left[{ }^{3} \mathrm{H}\right]$ thymidine incorporation during the last 18 hours of 3 -day cultures. For in vivo proliferation, cells were first labeled with $1 \mu \mathrm{M}$ CFSE for 5 minutes at $37^{\circ} \mathrm{C}$, then washed twice with ice-cold RPMI supplemented with $10 \%$ FCS, and resuspended in saline solution for i.v. injection. Spleen and lymph nodes were harvested for flow cytometric analysis at the indicated times.

Flow cytometric analysis. All flow cytometry analysis was conducted on a BD FACScalibur running CellQuest software. For surface staining, $5 \times 10^{5}$ cells were incubated with saturating concentrations of appropriate antibodies for 30 minutes at $4{ }^{\circ} \mathrm{C}$ in the dark, then washed twice in cold FACS buffer (PBS with $1 \%[\mathrm{v} / \mathrm{v}] \mathrm{FCS}$ and $0.01 \%[\mathrm{w} / \mathrm{v}]$ sodium azide) before analysis.

Skin transplantation. Skin transplantation was conducted as described previously (13). After removal of the plaster cast, the grafts were observed every 2-3 days. The graft was considered rejected when less than $10 \%$ of viable skin remained. Graft survival in the 2 groups was compared using the log-rank test.

Heterotopic heart transplant. Intra-abdominal heterotopic heart transplantation was performed as described by Niimi (38). Direct abdominal palpa- tion of heterotopically transplanted hearts was used to assessing the graft viability. Rejection was defined by complete cessation of cardiac impulses. It was confirmed by direct visualization and histological examination of the graft. Graft survival in the 2 groups was compared using the log-rank test.

Histological analysis. The heart grafts were embedded in paraffin, sectioned, and stained with $\mathrm{H} \& \mathrm{E}$ and elastin/van Gieson for histological evaluation. To evaluate the severity of transplant arteriosclerosis, the percentage of luminal occlusion was determined for each graft. The internal elastic lamina and the lumen were traced with Image-Pro plus software version 3 (Media Cybernetics), and the percentage of luminal occlusion was calculated by the formula: [(area within the internal elastic lamina - area of lumen)/area within the internal elastic lamina] $\times 100$.

Statistics. Data are expressed as mean \pm SEM or SD as indicated. Significance of difference between 2 groups was determined by unpaired 2-tailed Student's $t$ test. $P$ values less than 0.05 were considered statistically significant.

\section{Acknowledgments}

We would like to thank E. Leung for technical help, Angela Giorgini for help with the sections of the heart transplants, Domenico Spina for providing the DO11.10 mice, and A. Noble and M. Peakman for critical reading of the manuscript. This work was supported by the British Heart Foundation and RISET. H.J. Stauss and S.-A. Xue were supported by the Leukemia Research Fund. Y. Tanriver was supported by the German Research Foundation (grant Ta 436/1-1).

Received for publication July 3, 2007, and accepted in revised form August 20, 2008.

Address correspondence to: Robert Lechler, Immunoregulation Laboratory, Department of Nephrology and Transplantation, School of Medicine, Guy's Hospital, London SE1 9RT, United Kingdom. Phone: 44-207-8486980; Fax: 44-207-1887675; E-mail: robert.lechler@kcl.ac.uk.

Giovanna Lombardi and Robert Lechler are co-senior authors.
1. Sakaguchi, S. 2004. Naturally arising CD4+ regulatory $t$ cells for immunologic self-tolerance and negative control of immune responses. Annu. Rev. Immunol. 22:531-562.

2. Taylor, P.A., Lees, C.J., and Blazar, B.R. 2002. The infusion of ex vivo activated and expanded CD4(+) $\mathrm{CD} 25(+)$ immune regulatory cells inhibits graft-versus-host disease lethality. Blood. 99:3493-3499.

3. Cohen, J.L., Trenado, A., Vasey, D., Klatzmann, D. and Salomon, B.L. 2002. CD4(+)CD25(+) immunoregulatory T Cells: new therapeutics for graft-versus-host disease. J. Exp. Med. 196:401-406.

4. Cohen, J.L., and Boyer, O. 2006. The role of $\mathrm{CD} 4+\mathrm{CD} 25$ hi regulatory $\mathrm{T}$ cells in the physiopathogeny of graft-versus-host disease. Curr. Opin. Immunol. 18:580-585.

5. Graca, L., Cobbold, S.P., and Waldmann, H. 2002. Identification of regulatory $\mathrm{T}$ cells in tolerated allografts. J. Exp. Med. 195:1641-1646.

6. Hara, M., et al. 2001. IL-10 is required for regulatory $\mathrm{T}$ cells to mediate tolerance to alloantigens in vivo. J. Immunol. 166:3789-3796.

7. Rogers, N.J., and Lechler, R.I. 2001. Allorecognition. Am. J. Transplant. 1:97-102.

8. Hornick, P.I., et al. 2000. Significant frequencies of $\mathrm{T}$ cells with indirect anti-donor specificity in heart graft recipients with chronic rejection. Circulation. 101:2405-2410.

9. Baker, R.J., et al. 2001. Loss of direct and maintenance of indirect alloresponses in renal allograft recipi- ents: implications for the pathogenesis of chronic allograft nephropathy. J. Immunol. 167:7199-7206.

10. Wise, M.P., Bemelman, F., Cobbold, S.P., and Waldmann, H. 1998. Linked suppression of skin graft rejection can operate through indirect recognition. J. Immunol. 161:5813-5816.

11. Sanchez-Fueyo, A., et al. 2007. Influence of direct and indirect allorecognition pathways on CD4(+) $\mathrm{CD} 25(+)$ regulatory T-cell function in transplantation. Transpl. Int. 20:534-541.

12. Jiang, S., Camara, N., Lombardi, G., and Lechler, R.I. 2003. Induction of allopeptide-specific human CD4+CD25+ regulatory T cells ex vivo. Blood. 102:2180-2186.

13. Golshayan, D., et al. 2007. In vitro-expanded donor alloantigen-specific CD4+CD25+ regulatory T cells promote experimental transplantation tolerance. Blood. 109:827-835.

14. Tsang, J., et al. 2006. In-vitro generation and characterisation of murine CD4+CD25+ regulatory $\mathrm{T}$ cells with indirect allospecificity. Int. Immunopharmacol. 6:1883-1888.

15. Jiang, S., et al. 2006. Generation and expansion of human CD4+ CD25+ regulatory T cells with indirect allospecificity: Potential reagents to promote donor-specific transplantation tolerance. Transplantation. 82:1738-1743.

16. Honjo, K., Xu, X.Y., and Bucy, R.P. 2000. Heterogeneity of $\mathrm{T}$ cell clones specific for a single indirect alloantigenic epitope (I-Ab/H-2Kd54-68) that mediate transplant rejection. Transplantation. 70:1516-1524.

17. Honjo, K., Xu, X., and Bucy, R.P. 2004. CD4+ T-cell receptor transgenic $T$ cells alone can reject vascularized heart transplants through the indirect pathway of alloantigen recognition. Transplantation. 77:452-455.

18. Siegmund, K., et al. 2005. Migration matters: regulatory T-cell compartmentalization determines suppressive activity in vivo. Blood. 106:3097-3104.

19. Zheng, X.X., et al. 2003. Favorably tipping the balance between cytopathic and regulatory $\mathrm{T}$ cells to create transplantation tolerance. Immunity. 19:503-514.

20. Xia, G., He, J., Zhang, Z., and Leventhal, J.R. 2006. Targeting acute allograft rejection by immunotherapy with ex vivo-expanded natural CD4+ CD25+ regulatory T cells. Transplantation. 82:1749-1755.

21. Karim, M., Feng, G., Wood, K.J., and Bushell, A.R. 2005. CD25+CD4+ regulatory $\mathrm{T}$ cells generated by exposure to a model protein antigen prevent allograft rejection: antigen-specific reactivation in vivo is critical for bystander regulation. Blood. 105:4871-4877.

22. Joffre, O., et al. 2008. Prevention of acute and chronic allograft rejection with CD4+CD25+Foxp3+ regulatory T lymphocytes. Nat. Med. 14:88-92.

23. Nikolaeva, N., Bemelman, F.J., Yong, S.L., van Lier, R.A., and ten Berge, I.J. 2006. Rapamycin does not induce anergy but inhibits expansion and differentiation of alloreactive human $\mathrm{T}$ cells. Transplanta- 
tion. 81:445-454.

24. Strauss, L., et al. 2007. Selective survival of naturally occurring human $\mathrm{CD} 4+\mathrm{CD} 25+$ Foxp3+ regulatory $\mathrm{T}$ cells cultured with rapamycin. J. Immunol. 178:320-329.

25. Valmori, D., et al. 2006. Rapamycin-mediated enrichment of $\mathrm{T}$ cells with regulatory activity in stimulated CD4+ T cell cultures is not due to the selective expansion of naturally occurring regulatory $\mathrm{T}$ cells but to the induction of regulatory functions in conventional CD4+ T cells. J. Immunol. 177:944-949.

26. Battaglia, M., Stabilini, A., and Roncarolo, M.G. 2005. Rapamycin selectively expands CD4+CD25+FoxP3+ regulatory T cells. Blood. 105:4743-4748.

27. Jiang, S., Herrera, O., and Lechler, R.I. 2004. New spectrum of allorecognition pathways: implications for graft rejection and transplantation tolerance. Curr. Opin. Immunol. 16:550-557.

28. Morgan, R.A., et al. 2006. Cancer regression in patients after transfer of genetically engineered lymphocytes. Science. 314:126-129.

29. Masteller, E.L., et al. 2005. Expansion of functional endogenous antigen-specific $\mathrm{CD} 4+\mathrm{CD} 25+$ regulatory $\mathrm{T}$ cells from nonobese diabetic mice. J. Immunol. 175:3053-3059.

30. Rubinstein, M.P., et al. 2003. Transfer of TCR genes into mature $\mathrm{T}$ cells is accompanied by the maintenance of parental $\mathrm{T}$ cell avidity. J. Immunol. 170:1209-1217.

31. Schaft, N., et al. 2003. Peptide fine specificity of antiglycoprotein $100 \mathrm{CTL}$ is preserved following transfer of engineered TCR alpha beta genes into primary human T lymphocytes. J. Immunol. 170:2186-2194.

32. Rezvani, K., et al. 2006. High donor FOXP3-positive regulatory T-cell (Treg) content is associated with a low risk of GVHD following HLA-matched allogeneic SCT. Blood. 108:1291-1297.

33. Hanash, A.M., and Levy, R.B. 2005. Donor $\mathrm{CD} 4+\mathrm{CD} 25+\mathrm{T}$ cells promote engraftment and tolerance following MHC-mismatched hematopoietic cell transplantation. Blood. 105:1828-1836.
34. Read, S., Malmstrom, V., and Powrie, F. 2000. Cytotoxic $\mathrm{T}$ lymphocyte-associated antigen 4 plays an essential role in the function of CD25(+)CD4(+) regulatory cells that control intestinal inflammation. J. Exp. Med. 192:295-302.

35. Wells, A.D., Li, X.C., Strom, T.B., and Turka, L.A 2001. The role of peripheral T-cell deletion in transplantation tolerance. Philos. Trans. R. Soc. Lond. B Biol. Sci. 356:617-623.

36. Inaba, K., et al. 1992. Generation of large numbers of dendritic cells from mouse bone marrow cultures supplemented with granulocyte/macrophage colony-stimulating factor. J. Exp. Med. 176:1693-1702.

37. Willemsen, R.A., et al. 2000. Grafting primary human $\mathrm{T}$ lymphocytes with cancer-specific chimeric single chain and two chain TCR. Gene Ther. 7:1369-1377.

38. Niimi, M. 2001. The technique for heterotopic cardiac transplantation in mice: experience of 3000 operations by one surgeon. J. Heart Lung Transplant. 20:1123-1128. 